\title{
Narrative review of practical aspects of aerosol delivery via high-flow nasal cannula
}

\author{
Jie $\operatorname{Li}^{1} \wedge$, James B. Fink ${ }^{1,2}$ \\ ${ }^{1}$ Department of Cardiopulmonary Sciences, Division of Respiratory Care, Rush University Medical Center, Chicago, IL, USA; ${ }^{2}$ Aerogen Pharma \\ Corp, San Mateo, CA, USA \\ Contributions: (I) Conception and design: All authors; (II) Administrative support: J Li; (III) Provision of study materials or patients: J Li; (IV) \\ Collection and assembly of data: J Li; (V) Data analysis and interpretation: All authors; (VI) Manuscript writing: Both authors; (VII) Final approval of \\ manuscript: Both authors. \\ Correspondence to: Jie Li, PhD, RRT, RRT-ACCS, RRT-NPS, FAARC. 600 S Paulina St, Suite 765, Chicago, IL 60612, USA. Email: Jie_Li@rush.edu.
}

\begin{abstract}
Using high-flow nasal cannula (HFNC) as a "vehicle" to administer aerosolized medication has attracted clinicians' interest in recent years. In this paper, we summarize the current evidence to answer the common questions raised by clinicians about this new aerosol delivery route and best practices of administration. Benefits of trans-nasal aerosol delivery include increased comfort, ability to speak, eat, and drink for patients while meeting a range of oxygen requirements, particularly for those who need to inhale aerosolized medication for long periods. Aerosol administration via HFNC has been shown to be well tolerated by children and adults, with comparable or better delivery efficacy than other interfaces, ranging from 2-20\%. In vitro and in vivo scintigraphy studies among pediatric and adult populations reported that the inhaled dose delivered via a vibrating mesh nebulizer is 2 to 3 fold greater than that via a jet nebulizer. For adults, placement of nebulizer at the inlet of humidifier increases inhaled dose while reducing rainout obstructing nasal prongs. When HFNC gas flow is set below patient inspiratory flow, aerosol deposition is higher than when the gas flow exceeds patient inspiratory flow; thus, if tolerated, titrating down HFNC gas flow during trans-nasal aerosol delivery, with close monitoring and the use of unit dose with high concentration are recommended. Trans-nasal pulmonary aerosol delivery has not been shown to increase bioaerosols generated by patients, but gas flow may disperse aerosols. Placement of a surgical or procedure mask over HFNC might reduce aerosol dispersion.
\end{abstract}

Keywords: Aerosol therapy; high-flow nasal cannula (HFNC); oxygen therapy

Submitted Nov 10, 2020. Accepted for publication Mar 05, 2021.

doi: $10.21037 / \mathrm{atm}-20-7383$

View this article at: http://dx.doi.org/10.21037/atm-20-7383

\section{Introduction}

Conventional medical aerosol treatment is delivered using a range of aerosol devices, including nebulizers, metered dose inhaler (MDI) or dry powder inhaler (DPI), with connection to a mask or mouthpiece, mainly via oral route to patients' lower airway. In contrast, trans-nasal pulmonary aerosol delivery involves placing aerosol devices in-line with highflow nasal cannula (HFNC) system, in which the gas carries aerosolized medication via nasal cannula targeting patients' lungs $(1,2)$ (Figure 1). HFNC provides aerosol treatment along with warmed and humidified gas that significantly improves patients' comfort, which is particularly important for pediatric patients and long-term aerosol delivery. Thus this route has attracted increasing interest from clinicians (3). In this paper, we summarized the current evidence to answer the common questions raised by clinicians about this new

\footnotetext{
^ ORCID: 0000-0003-0121-1291.
} 


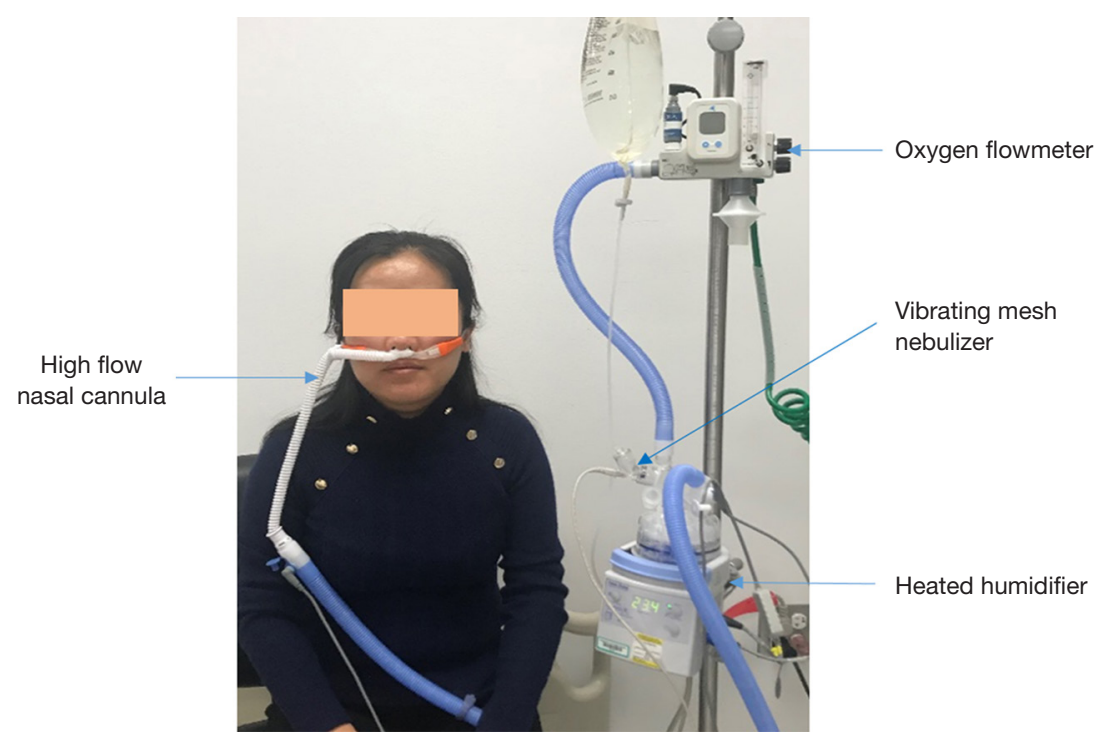

Figure 1 The set up for aerosol delivery via HFNC. Nebulizer (jet or vibrating mesh nebulizer) is placed at the inlet of humidifier (shown in figure), it could be placed at the outlet of humidifier and between the nasal cannula and HFNC circuit (not shown). HFNC, high-flow nasal cannula.

aerosol delivery route and best practices of administration. A search of the published English literature on these questions was conducted in PubMed, Medline, and Scopus from database origin to December of 2020. Peer reviewed in vitro/ bench studies, scintigraphy studies for animal or healthy volunteers, clinical retrospective and prospective studies, randomized controlled trials, and questionnaire surveys were included for review. We present the following article in accordance with the Narrative Review reporting checklist (available at http://dx.doi.org/10.21037/atm-20-7383).

\section{Compared to other aerosol delivery methods, what are the benefits of trans-nasal pulmonary aerosol delivery?}

Pediatric patients, especially infants and small children, are predominately nose-breathers; thus aerosol delivery via mouthpiece is not a viable option and nasal cannula offers an interface that fits their physiological needs. More importantly, sick kids can be easily irritated to cry by noise and cool aerosol that is generated by jet nebulizer (JN) with mask, or by sealed mask with spacer that is placed on their face to use MDI; while crying significantly reduces aerosol delivery compared to quiet breathing for pediatric patients (4). In contrast, small children tend to tolerate nasal cannula more readily than mask interfaces. As such, in-line placement of aerosol devices (nebulizers or MDI with spacer) with HFNC is beneficial, providing warm and humidified gas with aerosol therapy, with no need to touch patient's face or to change and reposition the interface. Compared to albuterol delivery via JN with mask for infants with bronchiolitis, patients appeared more comfortable after inhaling albuterol via vibrating mesh nebulizer (VMN) with HFNC $(5,6)$. HFNC is generally more convenient for older patients as well compared to mouthpieces and aerosol masks, which impede patient's ability to communicate, eat, and drink. In contrast, nasal cannula can be administered continuously over multiple days with minimal complaints by most patients.

In the acute and critical care settings, oxygen is commonly administered via HFNC to provide and maintain a consistent fraction of inspired oxygen. Removing HFNC to administer aerosol via mouthpiece or mask can interrupt oxygen and positive airway pressure. Placing a nebulizer inline with the HFNC allows the administration of medical aerosol without disrupting therapy.

Clinically, some patients require continuous inhaled dose administrated continuously for extended periods, such as inhaled albuterol for patients with status asthmaticus (7) or inhaled epoprostenol for patients with pulmonary hypertension and/or refractory hypoxemia (8-10). For this population, inhalation usually lasts for hours to days. Use of mouthpiece is typically limited to 20 minutes or less, and prolonged aerosol delivery by the mask is uncomfortable 
and reduces mobility, communication, and nutrition. Consequently, for extended aerosol administration, transnasal aerosol delivery via HFNC offers a feasible solution (2).

In all, for infants and small children who do not tolerate the mask, or anyone requiring long-term extended aerosol inhalation, trans-nasal pulmonary aerosol delivery provides an ideal option.

\section{Compared to conventional aerosol delivery methods, what is the delivery efficiency of trans- nasal pulmonary aerosol delivery?}

Standard jet nebulizer has reported delivery efficiencies of $1-10 \%$ (11-14). Compared to JN with mask, in vitro studies reported a similar inhaled dose was delivered using VMN via HFNC at common gas flow settings, including $2 \mathrm{~L} / \mathrm{min} / \mathrm{kg}$ for pediatric patients (13) and $50 \mathrm{~L} / \mathrm{min}$ for adult patients (14). In a comparison of aerosol administered via mouthpiece and mask during HFNC with aerosol administered via HFNC alone, Bennett and colleagues reported that aerosol via HFNC alone resulted in greater inhaled dose (14). Réminiac et al. confirmed these bench findings in a cross-over study of 25 stable patients with reversible airway obstruction, reporting similar bronchodilation effects with the same dose of albuterol delivered via VMN with HFNC at $30 \mathrm{~L} / \mathrm{min}$ and JN with mask (15). Furthermore, Bräunlich and Wirtz reported similar responses after inhaling bronchodilators via JN with mask versus with HFNC at $35 \mathrm{~L} / \mathrm{min}$ among 26 patients with stable chronic obstructive pulmonary disease (COPD) (16).

Patient response to $400 \mathrm{mcg}$ of albuterol via MDI with spacer has been reported to be comparable to a standard 2.5 $\mathrm{mg}$ dose of albuterol administered via VMN with HFNC delivering gas flow of $15-20 \mathrm{~L} / \mathrm{min}$ (17).

When aerosol is delivered via nebulizer or MDI with mask or mouthpiece over concurrent HFNC, the inhaled dose is much lower than aerosol delivery using the same device via mask or mouthpiece alone $(14,18)$ (Figure 2), probably because the high flow gas continuously enters the nose at rates higher than inspiration, and flushes the aerosol away from the airway. As such, placing a mask/mouthpiece with a nebulizer or MDI over HFNC should be avoided.

\section{How to provide trans-nasal pulmonary aerosol delivery?}

The delivery efficiency and effectiveness of trans-nasal pulmonary aerosol delivery are primarily dependent on the choices of type of nebulizer and their placement in different HFNC systems, the design and size of the nasal interface, and the gas flow settings during aerosol delivery.

\section{Nebulizer type}

$\mathrm{JN}$ and $\mathrm{VMN}$ are most commonly utilized to deliver aerosol via HFNC. In vitro and in vivo scintigraphy studies among pediatric and adult populations reported that the inhaled dose delivered via VMN with HFNC was 2 to 3 fold of that with JN $(11,12,19)$. This finding might be explained by little to no residual volume with $\mathrm{VMN}$ versus $0.5-1.5 \mathrm{~mL}$ residual volume with $\mathrm{JN}$, which contributes to $25-50 \%$ waste of the nominal dose. Unlike VMN powered by electricity, $\mathrm{JN}$ is powered by compressed gas source typically with a minimal gas flow of $6 \mathrm{~L} / \mathrm{min}$ to generate aerosol, which means the total HFNC gas flow would exceed $6 \mathrm{~L} / \mathrm{min}$ once $\mathrm{JN}$ is placed in-line with HFNC. This limits its use for small children whose gas flow should be no higher than $6 \mathrm{~L} / \mathrm{min}$ (2). Furthermore, this power gas mixed into the HFNC system alters the fraction of inspired oxygen $\left(\mathrm{F}_{\mathrm{I}} \mathrm{O}_{2}\right)$ in the HFNC delivered to the patient, limiting the use for patients with stringent requirements on $\mathrm{F}_{\mathrm{I}} \mathrm{O}_{2}$ such as COPD patients or children. Therefore, VMN is preferred for trans-nasal pulmonary aerosol delivery, especially for children (3).

\section{Nebulizer placement}

Similar to the results from invasive ventilation (20), inhaled dose was higher with nebulizer placed at the inlet of humidifier than that with nebulizer placed close to patient in both pediatric $(21,22)$ and adult $(23,24)$ in vitro studies, probably because the circuit and chamber can function as a reservoir for aerosol generated in the continuous mode.

Aerosol particle size impacts aerosol transit to the patient. The particles emitted from nebulizers most commonly have a mass median aerodynamic diameter (MMAD) of 4-6 microns. In contrast, aerosol particles exiting nasal cannula are reported to be less than 2 microns (23). This difference is due to a filtering effect when larger particles impact during transit through the delivery circuit creating rainout within the system. Nebulizer placement before the humidifier chamber allows larger aerosol particles to rainout into the humidifier chamber, reducing the collection of liquid downstream and at the patient interface. Placement of nebulizers immediately before the nasal cannula results in a greater proportion of the emitted 


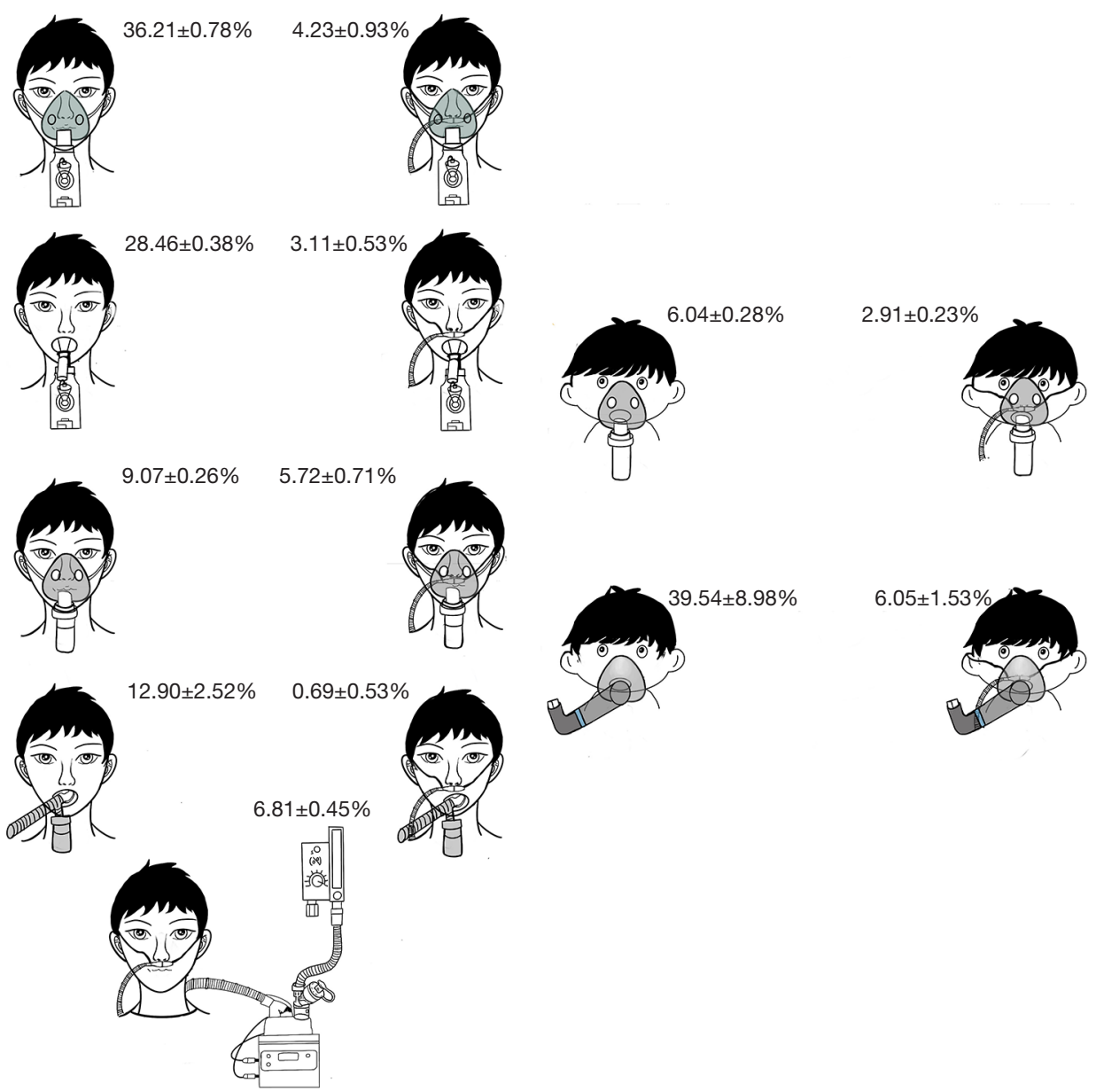

Figure 2 Comparisons of aerosol deposition with conventional nebulization via mouthpiece/mask alone (left) and with HFNC (right) in adult (A) and pediatric (B) patients. In the adult in vitro study (A), from top to bottom, Mesh nebulizer with mask, mesh nebulizer with mouthpiece, jet neb by mask, jet neb via mouthpiece and trans-nasal aerosol delivery with HFNC alone (bottom). Pediatric testing (B) jet neb with mask and metered dose inhaler via mask. Aerosol deposition varied from $9 \%$ to $36 \%$ with nebulization via mouthpiece or mask (left). In comparison, aerosol deposition with vibrating mesh nebulizer placed in-line with HFNC at $50 \mathrm{~L} / \mathrm{min}$ was $6.8 \%$ (middle), higher than nebulizer with mouthpiece/mask placed with concurrent HFNC at $50 \mathrm{~L} / \mathrm{min}$ (right). Similar findings were found in a pediatric in vitro study (B). Figures were modified from reference (14) and (18).

aerosol to rainout and collect in the cannula, where liquid tends to sputter, splash and periodically occlude the cannula and airway, causing discomfort and irritation of the patient while reducing aerosol delivery efficiency.

One position does not fit all sizes and flow rates. When gas flow was extremely low, such as $\leq 0.25 \mathrm{~L} / \mathrm{kg} / \mathrm{min}$ for infants, nebulizer placed proximal to patient generated higher inhaled dose than placed distal to patient (22), which might be explained that aerosol was deposited in the circuit before being transported to the patient, as for the low carrier gas flow. As such, nebulizer should be placed at the inlet of humidifier, except when extremely low gas flow is set for infant.

\section{High-flow nasal cannula system}

Currently, multiple manufacturers produce HFNC devices and interfaces. Some produce heated humidification systems explicitly designed for use with HFNC, while others simply provide cannula for use with other manufacturers' humidifiers. Due to the device design, the location for nebulizer placement is different. In some 
systems, a nebulizer can be placed at the inlet or outlet of the humidifier or close to the patient, such as Optiflow ${ }^{\mathrm{TM}}$ (Fisher \& Paykel Healthcare Ltd, Auckland, New Zealand). In contrast, with some designs, the nebulizer can only be placed close to patient due to the lack of appropriate adaptor or the humidification system's design, such as Airvo (Fisher \& Paykel Healthcare Ltd) or Precision Flow (Vapotherm, Stevensville, MD). When a VMN was placed proximal to the patient, Perry et al. reported that inhaled dose was only $0.2-2.5 \%$ for adult with gas flow at $5-40 \mathrm{~L} / \mathrm{min}$ and less or equal to $1 \%$ for pediatrics using the Vapotherm system (25), which was much lower than the inhaled dose reported with nebulizer placed at the humidifier in other studies that utilized Fisher \& Paykel system (11-15,17,18,22-24). This might be due to the nebulizer adapter's design, the size of the nasal cannula, or even the turbulent flow created in the HFNC system. Moreover, the size of the circuit affects aerosol deposition, Willis et al. reported that a larger size circuit had higher aerosol deposition (26). As each system is different, clinicians should expect aerosol performance data from both manufacturers and independent investigators to guide their device selection.

\section{Gas flow settings}

The peak inspiratory flow during quiet breathing generated by adult healthy volunteers with average height of 1.79 meter was reported to be $27.9 \pm 9.2 \mathrm{~L} / \mathrm{min}$ (27), thus HFNC is commonly set deliver flow of $50 \mathrm{~L} / \mathrm{min}$ or higher for adults and $2 \mathrm{~L} / \mathrm{kg} / \mathrm{min}$ for pediatrics, in order to exceed patient inspiratory flows, allowing for more consistent fraction of inhaled oxygen through the breathing cycle.

During quiet breathing and with nebulizer placed at the inlet of humidifier, both in vitro and in vivo deposition studies reported that inhaled dose increased as gas flow decreased in both pediatric $(22,28)$ and adult populations (23,24,29-32). Administration of radiolabeled aerosol with scintigraphy provides direct evidence of aerosol delivery efficiency to the lungs, upper airways and distribution to other compartment, including the device components and exhaled aerosol captured with a mask and filter (Figure 3) (31). Most importantly, the inhaled dose was found to peak when the gas flow was set around $50 \%$ of patient's inspiratory flow $(2,28,29)$. However, this finding is difficult to apply in clinical practice, as no commercial device is currently available to monitor patient's inspiratory flow, which may vary breath by breath. As such, a practical solution is to titrate gas flow based on patient's real-time response to the aerosolized medication, particularly for the medication that has a quick onset time and requires use for extended periods, such as inhaled bronchodilators and epoprostenol. A practical application of inhaled epoprostenol in Li et al.'s study was that HFNC flow was titrated down by $10 \mathrm{~L} / \mathrm{min}$ every 5-10 minutes, based on the changes of mean pulmonary arterial pressure for patients with pulmonary hypertension or saturation of pulse oximetry/ fraction of inspired oxygen $\left(\mathrm{SpO}_{2} / \mathrm{F}_{\mathrm{I}} \mathrm{O}_{2}\right)$ for hypoxemic patients, to seek for the flow when optimal response occurred (10).

\section{How to evaluate the in vivo efficacy of trans- nasal pulmonary aerosol delivery?}

The efficacy of aerosol delivery via HFNC can be evaluated using scintigraphy studies, which directly visualize and quantify the aerosol deposition in the lung $(11,19,28,31)$, but such studies are highly resource-dependent and are not realistic for critically ill patients to participate without compromising their care. Additionally, they are not convenient for general patients to assess immediately after the use of medication. Another measure is the pharmacodynamics study (33), which indirectly reflects the inhaled dose of aerosolized medication via the concentration of drugs in the blood or excreted in the urine within a certain period. However, this evaluation requires patients to have normal kidney function, and the medication should be deactivated in the gastrointestinal system once it is swallowed. The most commonly utilized assessment in clinical practice is via patients' clinical responses to the aerosolized medication, especially those with quick onset time, such as albuterol which can be evaluated by the forced expiratory volume at the first second in the spirometry tests $(15-17,32)$ and inhaled epoprostenol, evaluated with the changes of mean pulmonary arterial pressure $(9,10)$ or oxygenation (8-10). For medications like mucoactive, antiinflammatory, antiviral, and antibiotic medications that do not have rapid onset time or the effects cannot be readily quantified, further studies are needed to explore the ways to evaluate the efficacy of aerosol delivery for these agents.

\section{How to evaluate the risk of bioaerosol transmission with trans-nasal pulmonary aerosol delivery?}

In light of the recent pandemic of COVID-19, which is transmitted by contact, droplets, and airborne transmission, concerns have been raised that HFNC increases the risk 

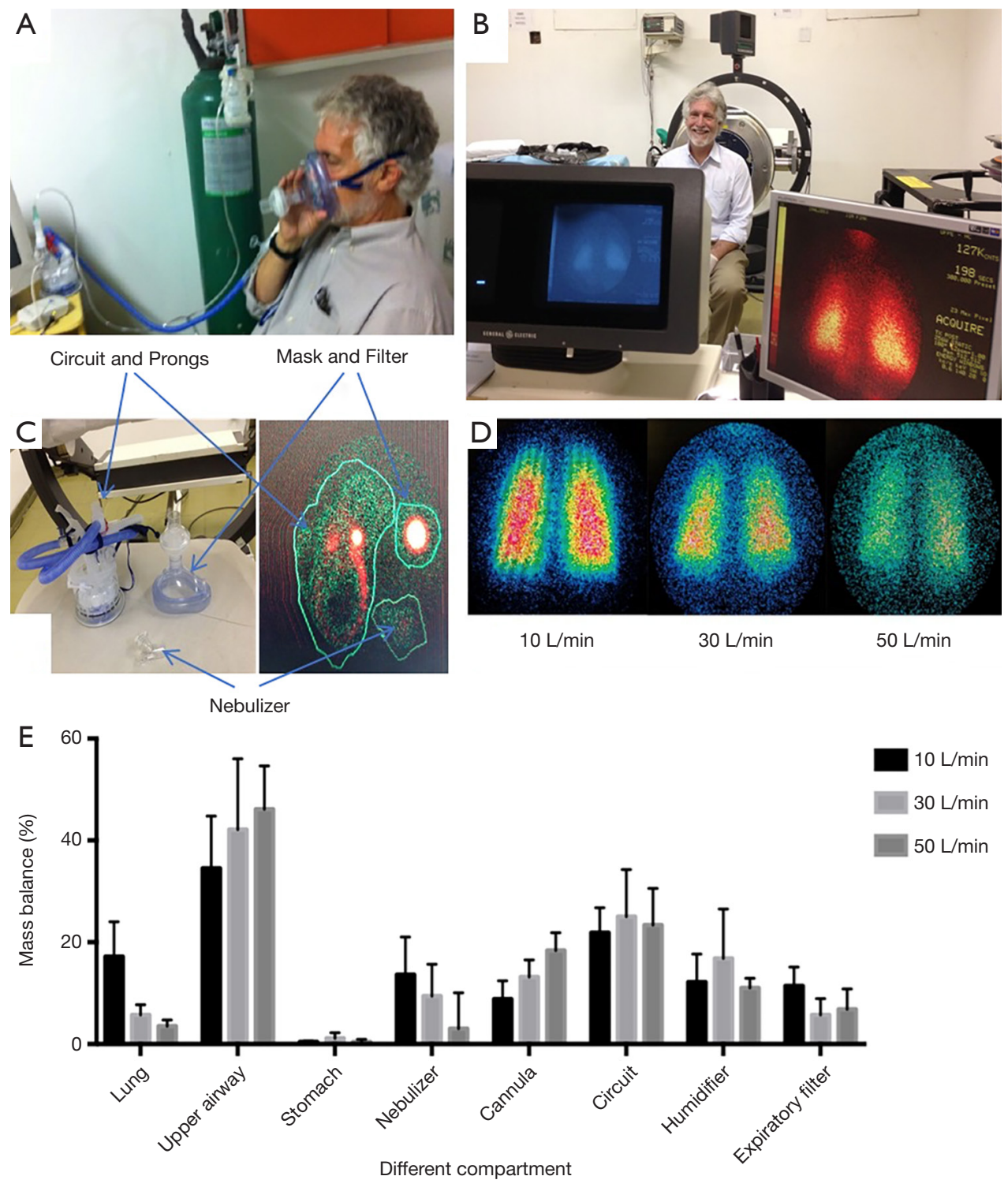

Figure 3 Radiolabel scintigraphy to determine lungs dose and mass balance. (A) Dosing with radiolabeled aerosol; (B) Imagining of thorax post inhalation; (C) Device components on scanner with representative scan; (D) Representative radiolabel images; (E) mass balance across different compartments at 10, 30 and $50 \mathrm{~L} / \mathrm{Min}$. After the subject inhaling radiolabeled aerosol via HFNC at different gas flows (A), the subject sat close to the gamma camera detector (B) to scan the anterior upper airway/face (C), followed by a scan of device components (nebulizer, humidifier chamber, tubing, cannula, mask, and filter) (C). Representative scans at gas flows of 10, 30 and 50 L/min (D) and result of aerosol deposition in different compartments at 10, 30 and $50 \mathrm{~L} / \mathrm{min}$ gas flows (E) were modified from (31).

of transmission of patient infected bioaerosols due to the high flows used (34). Some agencies have labeled HFNC as an aerosol generating procedure (AGP) (35). This led to the reluctance to use HFNC in COVID-19 patients, reducing available resources in managing critically ill patients at early pandemic. This is unfortunate as delaying intubation with the use of HFNC can substantially reduce immediate demand for ventilators. Medical aerosols do not have a mechanism for contamination if inhaled and then exhaled (36), and increased oxygen flow does not increase the amount of bioaerosols generated by the patient $(37,38)$. However, high gas flows may increase the dispersion of 


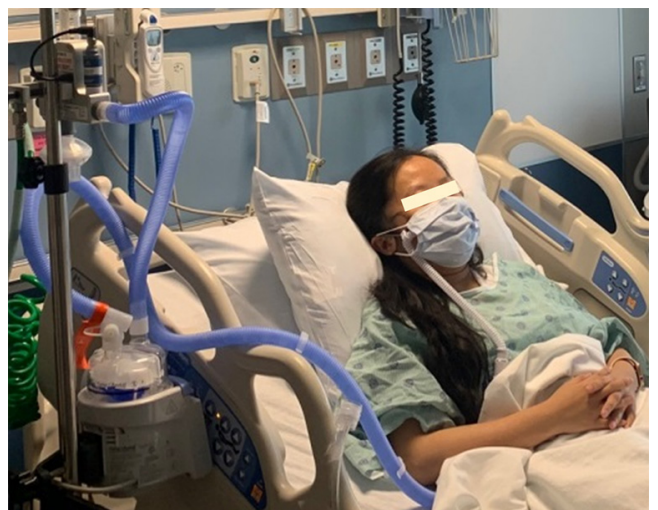

Figure 4 Placing a surgical mask over HFNC. HFNC, high-flow nasal cannula.

patient generated bioaerosols, increasing their radius of potential contamination (37). The scientific evidence of generation and dispersion of bioaerosols via HFNC show a similar risk to standard nasal cannula (38), while placing a surgical mask over the HFNC reduces the dispersion of aerosols, providing a reasonable practice to minimize transmission risk during the use of HFNC (38) (Figure 4).

\section{Summary}

The clinical efficacy in both adult and pediatric patients is similar between aerosol delivery via HFNC and conventional aerosol devices, such as small volume nebulizer or metereddose inhaler with spacer. Due to its comfort, trans-nasal aerosol delivery is particularly preferable for small children who are sensitive to cool aerosol and patients who need to inhale aerosolized medication for long periods. Compared to jet nebulizer, vibrating mesh nebulizer generates higher aerosol deposition, especially when it is placed at the inlet of humidifier inside HFNC system. When HFNC gas flow is set below patient inspiratory flow, aerosol deposition is higher than that with HFNC gas flow exceeding patient inspiratory flow; thus if tolerated, titrating down HFNC gas flow during trans-nasal aerosol delivery is recommended, with close monitoring and the use of unit dose with high concentration. Placement of a surgical or procedure mask over HFNC might reduce aerosol dispersion.

\section{Acknowledgments}

Funding: None.

\section{Footnote}

Provenance and Peer Review: This article was commissioned by the editorial office, Annals of Translational Medicine for the series "Medical Aerosol in Acute and Critical Care". The article has undergone external peer review.

Reporting Checklist: The authors have completed the Narrative Review reporting checklist. Available at http:// dx.doi.org/10.21037/atm-20-7383

Conflicts of Interest: Both authors have completed the ICMJE uniform disclosure form (available at http://dx.doi. org/10.21037/atm-20-7383). The series "Medical Aerosol in Acute and Critical Care" was commissioned by the editorial office without any funding or sponsorship. JBF served as the unpaid Guest Editor of the series. Dr. Li reports grants from Fisher \& Paykel Healthcare, during the conduct of the study; grants from Rice foundation, other from Fisher \& Paykel Healthcare, other from AARC, outside the submitted work. Dr. Fink is Chief Science Officer for Aerogen Pharma Corp, San Mateo, CA, USA. The authors have no other conflicts of interest to declare.

Etbical Statement: The authors are accountable for all aspects of the work in ensuring that questions related to the accuracy or integrity of any part of the work are appropriately investigated and resolved.

Open Access Statement: This is an Open Access article distributed in accordance with the Creative Commons Attribution-NonCommercial-NoDerivs 4.0 International License (CC BY-NC-ND 4.0), which permits the noncommercial replication and distribution of the article with the strict proviso that no changes or edits are made and the original work is properly cited (including links to both the formal publication through the relevant DOI and the license). See: https://creativecommons.org/licenses/by-nc-nd/4.0/.

\section{References}

1. Dugernier J, Reychler G, Vecellio L, et al. Nasal highflown for lung drug delivery: Theoretical, experimental, and clinical application. J Aerosol Med Pulm Drug Deliv 2019;32:341-51.

2. Li J, Fink JB, MacLoughlin R, et al. A narrative review on trans-nasal pulmonary aerosol delivery. Crit Care 
2020;24:506.

3. Miller AG, Gentle MA, Tyler LM, et al. High-flow nasal cannula in pediatric patients: A survey of clinical practice. Respir Care 2018;63:894-9.

4. Amirav I, Newhouse MT, Minocchieri S, et al. Factors that affect the efficacy of inhaled corticosteroids for infants and young children. J Allergy Clin Immunol 2010;125:1206-11.

5. Morgan SE, Mosakowski S, Solano P, et al. High-flow nasal cannula and aerosolized beta agonists for rescue therapy in children with bronchiolitis: A case series. Respir Care 2015;60:e161-5.

6. Valencia-Ramos J, Miras A, Cilla A, et al. Incorporating a nebulizer system into high-flow nasal cannula improves comfort in infants with bronchiolitis. Respir Care 2018;63:886-93.

7. Baudin F, Buisson A, Vanel B, et al. Nasal high flow in management of children with status asthmaticus: A retrospective observational study. Ann Intensive Care 2017;7:55.

8. Li J, Harnois LJ, Markos B, et al. Epoprostenol delivered via high flow nasal cannula for ICU subjects with severe hypoxemia comorbid with pulmonary hypertension or right heart dysfunction. Pharmaceutics 2019;11:281.

9. Ammar MA, Sasidhar M, Lam SW. Inhaled epoprostenol through noninvasive routes of ventilator support systems. Ann Pharmacother 2018;52:1173-81.

10. Li J, Gurnani PK, Roberts KM, et al. The clinical impact of flow titration on epoprostenol delivery via high flow nasal cannula for icu patients with pulmonary hypertension or right ventricular dysfunction: A retrospective cohort comparison study. J Clin Med 2020;9:464.

11. Réminiac F, Vecellio L, Loughlin RM, et al. Nasal high flow nebulization in infants and toddlers: An in vitro and in vivo scintigraphic study. Pediatr Pulmonol 2017;52:337-44.

12. Ari A. Effect of nebulizer type, delivery interface, and flow rate on aerosol drug delivery to spontaneously breathing pediatric and infant lung models. Pediatr Pulmonol 2019;54:1735-41.

13. Li J, Wu W, Fink JB. In vitro comparison of unit dose vs infusion pump administration of albuterol via high-flow nasal cannula in toddlers. Pediatr Pulmonol 2020;55:322-9.

14. Bennett G, Joyce M, Fernandez EF, et al. Comparison of aerosol delivery across combinations of drug delivery interfaces with and without concurrent high-flow nasal therapy. Intensive Care Med Exp 2019;7:20.

15. Réminiac F, Vecellio L, Bodet-Contentin L, et al. Nasal high-flow bronchodilator nebulization: A randomized cross-over study. Ann Intensive Care 2018;8:128.

16. Bräunlich J, Wirtz H. Oral versus nasal high-flow bronchodilator inhalation in chronic obstructive pulmonary disease. J Aerosol Med Pulm Drug Deliv 2018;31:248-54.

17. Li J, Zhao M, Hadeer M, et al. Dose response to transnasal pulmonary administration of bronchodilator aerosols via nasal high-flow therapy in adults with stable chronic obstructive pulmonary disease and asthma. Respiration 2019;98:401-9.

18. Alalwan MA, Fink JB, Ari A. In vitro evaluation of aerosol drug delivery with and without high flow nasal cannula in children. Pediatr Pulmonol 2019;54:1968-73.

19. Dugernier J, Hesse M, Jumetz T, et al. Aerosol delivery with two nebulizers through high-flow nasal cannula: A randomized cross-over single-photon emission computed tomography-computed tomography study. J Aerosol Med Pulm Drug Deliv 2017;30:349-58.

20. Ari A, Atalay OT, Harwood R, et al. Influence of nebulizer type, position, and bias flow on aerosol drug delivery in simulated pediatric and adult lung models during mechanical ventilation. Respir Care 2010;5 5:845-51.

21. Sunbul FS, Fink JB, Harwood R, et al. Comparison of hfnc, bubble cpap and sipap on aerosol delivery in neonates: An in-vitro study. Pediatr Pulmonol 2015;50:1099-106.

22. Li J, Gong L, Ari A, Fink JB. Decrease the flow setting to improve trans-nasal pulmonary aerosol delivery via "high-flow nasal cannula" to infants and toddlers. Pediatr Pulmonol 2019;54:914-21.

23. Réminiac F, Vecellio L, Heuze-Vourc'h N, et al. Aerosol therapy in adults receiving high flow nasal cannula oxygen therapy. J Aerosol Med Pulm Drug Deliv 2016;29:134-41.

24. Li J, Wu W, Fink JB. In vitro comparison between inspiration synchronized and continuous vibrating mesh nebulizer during trans-nasal aerosol delivery. Intensive Care Med Exp 2020;8:6.

25. Perry SA, Kesser KC, Geller DE, et al. Influences of cannula size and flow rate on aerosol drug delivery through the vapotherm humidified high-flow nasal cannula system. Pediatr Crit Care Med 2013;14:e250-6.

26. Willis R, Lowe G, Berlinski A. Effect of circuit size on albuterol delivery during heated high-flow nasal cannula therapy in a pediatric model. Respir Care 2018;63:3019833.

27. Ritchie JE, Williams AB, Gerard C, et al. Evaluation of a humidified nasal high-flow oxygen system, using 
oxygraphy, capnography and measurement of upper airway pressures. Anaesth Intensive Care 2011;39:1103-10.

28. Corcoran TE, Saville A, Adams PS, et al. Deposition studies of aerosol delivery by nasal cannula to infants. Pediatr Pulmonol 2019;54:1319-25.

29. Dailey PA, Harwood R, Walsh K, et al. Aerosol delivery through adult high flow nasal cannula with heliox and oxygen. Respir Care 2017;62:1186-92.

30. Li J, Gong L, Fink JB. The ratio of nasal cannula gas flow to patient inspiratory flow on trans-nasal pulmonary aerosol delivery for adults: An in vitro study. Pharmaceutics 2019;11:225.

31. Alcoforado L, Ari A, Barcelar JM, et al. Impact of gas flow and humidity on trans-nasal aerosol deposition via nasal cannula in adults: A randomized cross-over study. Pharmaceutics 2019;11:320.

32. Li J, Luo J, Chen Y, et al. Effects of flow rate on transnasal pulmonary aerosol delivery of bronchodilators via high-flow nasal cannula for COPD and asthma patients: protocol for a randomized controlled trial. BMJ Open 2019;9:e028584.

Cite this article as: Li J, Fink JB. Narrative review of practical aspects of aerosol delivery via high-flow nasal cannula. Ann Transl Med 2021;9(7):590. doi: 10.21037/atm-20-7383
33. Madney YM, Fathy M, Elberry AA, et al. Aerosol delivery through an adult high-flow nasal cannula circuit using lowflow oxygen. Respir Care 2019;64:453-61.

34. Li J, Fink JB, Ehrmann S. High-flow nasal cannula for COVID-19 patients: low risk of bio-aerosol dispersion. Eur Respir J 2020;5 5:2000892.

35. Harding H, Broom A, Broom J. Aerosol-generating procedures and infective risk to healthcare workers from SARS-CoV-2: the limits of the evidence. J Hosp Infect 2020;105:717-25.

36. Fink JB, Ehrmann S, Li J, et al. Reducing aerosol-related risk of transmission in the era of COVID-19: An interim guidance endorsed by the International Society of Aerosols in Medicine. J Aerosol Med Pulm Drug Deliv 2020;33:300-4.

37. Dhand R, Li J. Coughs and sneezes: Their role in transmission of respiratory viral infections, including SARSCoV-2. Am J Respir Crit Care Med 2020;202:651-9.

38. Li J, Fink JB, Elshafei AA, et al. Placing a mask on COVID-19 patients during high-flow nasal cannula therapy reduces aerosol particle dispersion. ERJ Open Res 2021;7:00519-2020. 